\title{
Species Natures: A Critique of Neo-Aristotelian Ethics
}

By Tim Lewens

\begin{abstract}
This paper examines the neo-Aristotelian account of species natures as 'life-forms', which we owe to Philippa Foot, Michael Thompson and their defenders. I begin by developing two problems for their view: a problem of underdetermination, and a problem generated by psychological work on 'folk essentialism'. I move on to consider their important transcendental argument, which suggests that claims about life-forms are presupposed by all efforts to describe the organic world. In response, I sketch a neo-Kantian projectivist position, which agrees that life-forms are presupposed in these contexts, while denying that such life-forms are real. This position makes better sense of the phenomena cited in support of the neo-Aristotelian view, while avoiding the problems raised for that view in the first half of the paper.
\end{abstract}

Keywords: species natures, life-forms, Philippa Foot, Michael Thompson, neoAristotelianism, Kantian projectivism. 


\section{SPECIES NATURES AS LIFE FORMS}

This paper is concerned with the neo-Aristotelian approach to species natures associated with Philippa Foot (2001) and Michael Thompson (1995; 2004; 2008), and defended by Micah Lott (2012) and John Hacker-Wright (2009) among others. Thompson and Foot deny that claims about species natures can be reduced to a set of more basic claims stated in the technical language of the biological sciences. To describe the nature of the domestic dog, they say, is not to describe what is statistically common among individuals of the biological species Canis familiaris. Nor is it to say something about the biological functions of the traits of these individuals, where 'biological function' is understood in terms of facts about contributions to reproductive fitness, or to past regimes of natural selection. ${ }^{1}$ On Thompson's view, we describe a species nature by describing that species' 'life form'.

Thompson and Foot appear to believe that there are facts about these life forms. These facts constitute how a given species of living being makes its way in the world, hence they carry normative implications for what counts as a defective individual of the type in question. These facts, says Thompson, are presupposed by the very act of categorising an individual as involved in organismic activity. In particular, they are presupposed whenever we describe an organism as engaged in some kind of 'vital operation' - copulating, migrating, transpiring, excreting, or any other process of life (Thompson 2008, 46). We cannot make a start on describing the natural world without conceiving of individuals as

\footnotetext{
${ }^{1}$ See Neander (1991), Griffiths (1993), Walsh and Ariew (1996), for efforts to analyse the notion of biological function.
} 
belonging to a species, understood as a 'life-form'. In that sense, life-forms come prior to technical biological inquiry.

Section two of this article begins with a more detailed presentation of the neo-Aristotelian view of species natures. I focus on whether it is fair to depict Foot and Thompson as committed to a broadly realist position, whereby there are facts of the matter about species natures, to which our judgements answer with greater or lesser success.

Foot and Thompson are quite explicit that the notions of function, species and related terms that characterise their approach are not the same as the concepts of 'function' and 'species' that appear in the technical biological articles. In sections three, four and five of this article I raise some prima-facie worries that derive from this feature of neo-Aristotelianism. On the one hand, this move protects Foot and Thompson's views from refutation by appeal to biological work: they have quite distinct concerns to those of (for example) evolutionary theorists. On the other hand, the move exposes them to worries about underdetermination. ${ }^{2}$ Having denied that species natures can be straightforwardly reduced to the sorts of facts dealt with by biological researchers, it becomes unclear what makes it the case for Foot and Thompson that a species nature is one way, rather than another.

In section six I add a further set of concerns that derive from psychological research on 'folk essentialism' (e.g. Atran 1990; Atran et al. 1997; Gelman and Hirschfeld 1999). Even if Foot and Thompson are right that we conceive of species as having natures of a neo-Aristotelian

\footnotetext{
${ }^{2}$ See Woodcock 2015.
} 
sort, work on folk essentialism gives no reason to think there are any facts about these natures (Glackin 2016).

These considerations do not address what is probably the most compelling positive argument in favour of the neo-Aristotelian position. Foot and Thompson hold that our understanding of the living world presupposes that we think of every token organism as instantiating (more or less well) a 'life-form' associated with its species. They argue that claims about life-forms are conceptually prior to the sorts claims that biological scientists might make, and are unavoidable if we are to characterise some parts of the world around us as living at all.

I respond in section seven by sketching a neo-Kantian, rather than a neo-Aristotelian, position. Hacker-Wright (2009) has claimed that we should recognise a strong current of Kantian ethics in Thompson and Foot's work. Here I argue for a Kantian approach to biology that is more threatening to their neo-Aristotelianism. Even if: (i) it is necessary to conceive of the organic world in terms of species natures, life-forms and the like; (ii) talk about such life-forms cannot be reduced to any more basic biological or scientific claims; and (iii) such claims have normative content, these propositions do not entail that there are such lifeforms, or natures. Instead, a 'Kantian projectivist' view - which draws on prior work by Lewens (2007) and especially Breitenbach (2009)-is more attractive. On this view, we organise the unruly empirical mess of the biological world by projecting a finite number of proper developmental outcomes onto what would otherwise be an unmanageable diversity. 
Kantian projectivism avoids any need to posit a domain of facts about life-forms that is distinct from facts treated by technical biological inquiry, and it offers a ready explanation for the phenomena of underdetermination reviewed in the middle part of the article. This projectivist view thus gives us a way of making sense of the phenomena of 'vital description' that Thompson and Foot draw our attention to, but in a way that seems ill-suited to a realist understanding of normative judgement.

\section{A PRIMER ON ARISTOTELIAN REALISM}

I am concerned here solely with the neo-Aristotelian project associated with Philippa Foot, Michael Thompson and their defenders. I make no claims about the standing of related views of Martha Nussbaum. I also make no claims about the Aristotelian position in biology defended by Denis Walsh (2006; 2015). This section offers an overview of the Foot/Thompson approach.

Thompson notes that in spite of its singular surface form, a sentence like 'The bobcat breeds in the spring', at least when we find it in a nature documentary or a field-guide, is not saying something about one individual bobcat. Instead, it aims at a more general form of description. That said, the form of generality is not a simple statistical one: we cannot reduce 'The $\mathrm{S}$ is $\mathrm{F}$ ' to 'All Ss are $\mathrm{F}^{\prime}$ or even to 'The majority of Ss are $\mathrm{F}^{\prime}$. Thompson backs this claim up via the observation that 'The mayfly breeds before dying' is not challenged by the fact that most mayflies die without breeding at all. 
Thompson calls sentences that have the general structure 'The $\mathrm{S}$ is/has F' Aristotelian categoricals. Such sentences are just one way to express what he calls 'natural historical judgements' (1995: 281). These judgements can also be expressed in the form 'Ss are/have $F^{\prime}$ ', as well as via many other locutions. Consider, in support of this, that 'The tiger has stripes' and 'Tigers have stripes' seem interchangeable.

Thompson takes it that these judgements tell us something about the 'life-form' for the species in question. In so doing, they specify standards, which members of the species should meet, and which a large proportion of actual members may fail to meet. This means that natural historical judgements have normative implications. If Fido is a dog with three legs, and if a true natural historical judgement is expressed via 'the domestic dog has four legs', then these two claims (on Thompson's view) entail that Fido is defective. ${ }^{3}$ This does not mean that the defects in question are of a moral character. Foot, for example, does not try to suggest that an oak with defective roots is thereby an evil oak. On her view, ethical evaluation applies specifically to defective practical reason. But an evil person is one whose practical reason is defective, and this faculty is defective in just the same sense that a wobbly oak tree's roots are defective: 'I want to show moral evil as "a kind of natural defect"' (Foot 2001: 5).

Thompson's observations on natural historical judgements are prompted by reflecting on 'the voice-overs on public television nature programmes' (1995: 280), more than by reflecting on the contents of biological research articles. Just as the objects of Thompson

\footnotetext{
${ }^{3}$ Thompson (1995: 295).
} 
and Foot's analyses are not technical, scientific notions, so the resources they draw on to provide their analyses are not taken from technical details of the life sciences either. For example, Foot is clear that when she articulates a notion of 'function', this is not meant to be an analysis of the notion of function as used in evolutionary theory (2001: 32). Her account does not compete with the kind of evolutionary analysis of 'proper function' given by people like Karen Neander (1991).

The same goes for Thompson's use of the term 'species':

... a concept is a species concept if it is a possible subject of [a natural historical judgement]. A life-form or 'species' (in the broad sense) is anything that is, or could be, immediately designated by a species concept or life-form word. (Thompson 1995: 292)

A species, for Thompson, is the sort of thing that might be accurately described via a natural historical judgement.

This means that what biologists would regard as sub-specific morphs, rather than true species, might be species in Thompson's sense. One of Thompson's first examples of a natural historical judgement, drawn from an imaginary nature documentary voiceover, is expressed via the phrase '...the female bobcat gives birth to two to four cubs' (1995: 280, emphasis added). No biologist believes that 'the female bobcat' designates a species. The marine crustacean species Paracerceis sculpta has three very different male forms, including one 'cryptic' form that looks just like a female (Schuster 1987). 'The cryptic male form of 
Paracerceis Sculpta sneaks into sponges to grab mating opportunities' seems to express a natural historical judgement, and so 'the cryptic male form' might designate a species for Thompson, even though it does not designate a species for any biologist.

This is not meant as a criticism of Thompson. His remarks about using the term 'species' in 'a broad sense', and his explicit use of 'species' as an alternative to 'life-form', suggest he is well aware that what we might call T-species-i.e. Thompson-species, understood as those entities that can be described through natural historical judgements-are not supposed to correspond in any straightforward manner with the species that biological systematists would recognise.

While the notions or function, species and so forth that Foot and Thompson draw on are not meant to be connected in any close way with technical biological concepts, their view appears to be a realist one nonetheless (Hacker-Wright 2009). That is because there are supposed to be facts about life-forms, which natural historical judgements sometimes succeed in stating. In claiming 'The bobcat breeds in the spring', we state a fact about the bobcat's form of life.

I do not think this interpretation of Foot and Thompson as realists is assured. In favour of it, consider Foot's (2001: 5) assertion: 'the fact that a human action or disposition is good of its kind will be taken to be simply a fact about a given feature of a certain kind of living thing.' That seems to imply that, for Foot, there are kinds of living things-namely species, or lifeforms - and there are facts about them that we may get right or wrong. We have also seen that, for Thompson, 'A life-form...is anything that is, or could be, immediately designated by 
a species concept or life-form word.' Again, we might take this to indicate that, on Thompson's view, there are life-forms, which we can describe with greater or lesser accuracy.

Unfortunately things are not so simple. Thompson tells us that we should 'cast aside' any image of a life-form as something that might be 'in a platonic heaven, or in the mind of God... of something "within"...or of something somehow "above".' Thompson rejects all such simple efforts to locate or ground these life-forms. Instead he writes that, 'our question should not be: What is a life-form, a species, a psuchēe, but: How is such a thing described?' (2008: 62). So perhaps Thompson is trying to show how we deploy the notion of life-form in our descriptions of nature, and why we must deploy the notion in that way, with no further implication that there are facts of the matter about life-forms, or even that there are lifeforms.

Likewise, Foot opens Natural Goodness by telling the reader that her overall task is 'to describe a particular type of evaluation and to argue that moral evaluation of human action is of this logical type' (2001: 3). She explicitly identifies her target as the various forms of non-cognitivism and expressivism:

...when I was told by a certain philosopher who wanted to explain 'good' in terms of choices, that good roots of trees were roots of the kind we 'should choose if we were trees', this finally confirmed my suspicions of the kind of moral philosophy that was his. (25-6) 
Perhaps Foot is attempting to persuade us that our judgements purport to describe lifeforms understood in a certain kind of way, while leaving open the questions of whether there are such life-forms.

In Foot's case it seems a stretch to cut her views on the interpretation of moral judgement entirely loose from realism about species natures. Consider her comment that:

Nobody would, I think, take it as other than a plain matter of fact that there is something wrong with the hearing of a gull that cannot distinguish the cry of its own chick, as with the sight of an owl that cannot see in the dark. It is obvious that there are objective, factual evaluations of such things as human sight, hearing, etc., based on the life form of our own species. (2001: 24)

Here Foot seems to be avowing a realist position that recognises facts about life forms.

Thompson does not, to my knowledge, explicitly disagree with Foot's apparently realist commitments. He also spends a good amount of time (as I will explain in section 4) outlining how we go about confirming or disconfirming particular claims about species natures. This all speaks to a kind of realism on Thompson's part. Even so, we have also seen that many of Thompson's comments indicate a primary focus on the form of our judgements about nature, not on whether those judgements succeed in stating facts. It is consequently unclear how exactly we should position Thompson. While he rejects any strongly metaphysically loaded form of realism-Platonism about life-forms, for example-there are indications that 
he believes that we can make mistakes about life-forms, and that in some cases what we say about them can be correct.

In the face of this uncertainty about how to interpret Thompson, I will proceed by cautiously assuming that a minimal form of realism characterises his position. He seems to think that life-forms can be described with greater or lesser accuracy; he seems to think some of our judgements about life-forms are likely to be correct; and he seems opposed to any view which denies the existence of life-forms. I raise a set of prima-facie problems for this minimal realist view over the course of this article. I suggest that a neo-Kantian form of antirealism about life forms explains why the realist position faces prima-facie problems, it does not face the same problems itself, and it offers an alternative way of making sense of the considerations that motivate the positive argument for the realist position.

The anti-realist position proposed here accords with Thompson's view that claims about life-forms cannot be reduced to more basic claims stated in the technical language of the biological sciences. It also accords with Thompson's view that the very practice of biological investigation necessitates the use of such life-form concepts. What is more, I will argue that there are empirical constraints on which specific life-form claims it makes sense to endorse. This accords with Thompson's view, too.

There is a considerable risk, in light of the ambiguity we have seen regarding whether Thompson is a realist about life-forms at all, that the anti-realist position offered here simply is Thompson's own view. Should that be the case, this article will not work as an attack on his version of neo-Aristotelianism. That would not make the present article 
without value, for it will have resolved some ambiguity in Thompson's position, and offered a strengthened defence of it.

\section{UNDERDETERMINATION: THE PRICE OF BIOLOGICAL UNMOORING}

Which T-Species should we recognise? In the Descent of Man, Darwin cites with approval some exceptionally offensive remarks from William Greg about people from Ireland. Greg says that 'The careless, squalid unaspiring Irishman multiplies like rabbits' (Darwin 1877/2004: 164).

One imagines that Thompson would say that Greg is expressing a natural historical judgement about 'The Irishman'. Greg's comments aim at general description, and they have the form of an Aristotelian categorical. A previous reader has suggested that Thompson might deny that Greg expresses a natural historical judgement, on the grounds that for Thompson, 'It is necessary that a common noun (" $\mathrm{S}$ ") and some other predicative expression ("F") be present or in the offing' (2008: 65, emphasis added).

It seems clear from context, though, that Thompson here uses 'common noun' to draw a distinction between attempts to describe named individuals via proper nouns-his example is 'Tibbles' the cat-and attempts 'at natural history', which instead aim at general description. Given that Greg's comment aims at general description, 'The Irishman' surely counts as a common noun for Thompson's purposes-just as 'Lady Amherst's pheasant' (Chrysolophus amherstiae) would-in spite of the appearance of capital letters in both phrases. 
Presumably Thompson would deny the truth of Greg's judgement, perhaps becauseunlike 'The female bobcat' - there is no T-species that is denoted by 'The Irishman'. But on Thompson's account, Greg's judgement cannot be dismissed merely by pointing out that biologists would not recognise the Irish as a species, nor by pointing out that the great majority of Irish people do not multiply like rabbits. So what allows us to decide whether 'The Irishman' denotes a bona-fide T-species, and if so what can be truly asserted of the lifeform of such a T-species?

My general concern is that since Thompson and Foot explicitly deny that there is any simple relationship between natural historical judgements and statistical facts, and since they also deny that natural historical judgements can be understood in terms of articulating the sorts of evolutionary function claims that reduce claims about malfunction to claims about regimes of natural selection, it is unclear what makes it the case that some natural historical judgements are true, while other competing ones are false.

My argument here is close to Woodcock's (2015), but while his tends to focus on difficult questions about the human life form, mine encompasses claims about the life-forms of plant and animal species. One explanation for this form of underdetermination-an explanation congenial to the neo-Aristotelian-is that it is difficult to know in any precise way about how things are with species natures. Another explanation, also tolerable to the Aristotelian realist, is that while species natures are real, there are some questions about their features that have no answers. A third explanation-and ultimately, I shall argue, a 
more attractive one-is that there are no species natures, understood as life-forms in the Aristotelian sense.

Consider a claim such as 'The human lives until 110'. Is it true, when understood as a description of a life-form? The global human life expectancy at birth is around 70 years, according to the UN's 2015 World Population Prospects report (UN 2015). On Thompson's view, the fact that the great majority of humans do not get close to 110 does not suffice to show that our candidate natural historical judgement is false, for perhaps we should simply take very occasional long life as evidence that most humans are defective. Consider the alternative claim, 'The human lives until $60^{\prime}$. The fact that a large number of humans do make it to this age does not speak directly to its truth on the Thompson/Foot view. That is because if the judgement is true, then (for Thompson, although not for Foot as we will shorty see) it entails that a human who dies at 50 is defective. But the mere fact that most humans happen to pass this age does not show earlier death is improper for humans, any more than if most humans made it to 90 this would show that dying at 75 is improper.

There is a body of theory in sociobiology (e.g. Hawkes 2003) which suggests that the fact of living for several years after direct reproduction has ceased might be explicable by the ways in which grandparents help to raise children. We might try to argue that humans have been selected for living past 50 years of age, hence humans who die younger are malfunctioning according to a biological standard derived from claims about the history of a population's exposure to natural selection. But Thompson and Foot resist using these sorts of sociobiological reflections to show, in any direct way, which natural historical judgements are true. 
Similar concerns can be raised about natural historical judgements that concern non-human animals. Consider, 'The chimpanzee practices infanticide'. Adult chimps-both male and female-have been observed to kill infant chimps (Arcadi and Wrangham 1999). Is our sentence true, when understood as expressing one of Thompson's natural historical judgements? If we regard such a judgement as true, then we are committed to regarding a chimp that does not practice infanticide as defective (although not immoral, as we saw earlier). So, what resources do we have for deciding on this matter?

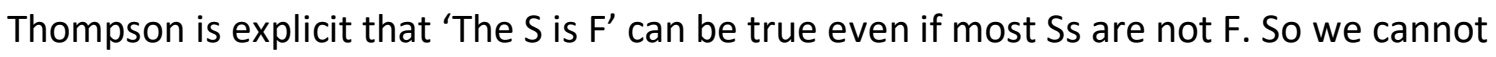
determine the truth of 'The chimp practices infanticide' by looking at what proportion of chimps engage in this behaviour. Considerations from sociobiology suggest a number of different ways in which infanticide might have evolutionary functionality, in the sense of boosting the reproductive fitness of chimps (ibid.). Infanticide by females may lower resource competition, or provide nutritional benefit via cannibalism. Infanticide by males may eliminate rivals in future competitions. It might also constitute a form of threat to coerce sexual monopoly. But, again, Thompson and Foot are explicit in distancing themselves from any straightforward appeal to evolutionarily-grounded notions of function and fitness when determining the truth of natural historical judgements. In short, by unmooring their theory from the technical realm of biology, their approach leaves the question of whether, 'The chimp practices infanticide' is true unclear, in the sense that it is unclear what determines its truth. 
My worries here have some surface commonality with Fitzpatrick's (2000), but our basic objections are different. He draws on ugly-looking cases from sociobiology, such as the injurious warring over mates which male elephant seals engage in, to cast doubt on the Foot/Thompson view:

Can we really suppose that animals fighting desperately with their peers simply in order to out-reproduce them are thereby acting 'for their good', or for any organism's good for that matter...? On the contrary, it seems elephant seals could at least in principle get on just as well without these traits - perhaps even better, expending less energy fighting, avoiding the inevitable injuries, and so on.

(Fitzpatrick 2000: 73)

Lott (2012) responds on behalf of Foot and Thompson, suggesting that while it might seem to us that their competitions are wasteful or unnecessary, investigation reveals that, for elephant seals, their characteristic way of life does indeed involve competitive struggle over mates. An elephant seal that cannot compete really is a defective instance of the species. The mere fact that we might be disturbed to learn what makes for a good elephant seal, says Lott, is irrelevant to the Thompson/Foot view. Theirs is not a theory about what we might find admirable, it is a theory about what counts, as a matter of fact, as a defective instance of a given life-form:

For birds of paradise and elephant seals, it turns out, the process of finding a mate and reproducing is a competitive one; that is their characteristic way of reproducing. (Lott 2012: 365) 
At this point we can clarify why my objection requires a different type of response. I am not trying to use any unsavoury evaluation we might come to of chimp infanticide to cast doubt on the idea that a good chimp might be one that practices infanticide. Instead, my worry concerns what makes it the case, on Foot and Thompson's view, that a proper chimp practices infanticide. I now turn to Thompson's own remarks on this matter, before briefly considering Foot's suggestions for how to determine what she calls 'general (species-based) criteria of evaluation' (2001: 18).

\section{THOMPSON ON THE EPISTEMOLOGY OF NATURAL HISTORICAL JUDGEMENTS}

Thompson has a positive account about how we can determine which natural historical judgements to assert. He suggests that through long and detailed investigation of the natural world we slowly build up a picture of which species we should recognise, and what we should say about their characteristic ways of getting on. For example, he imagines a naturalist with considerable expertise regarding jellyfish (Thompson 2004). One day, this naturalist notices several jellyfish of a conformation she-and her colleagues-have not seen before. They are small, with unusual arrangements of tentacles. Thompson's general approach requires that there are good answers to questions such as, 'Are these creatures defective instances of a species we already know about, are they well-functioning members of a species not previously recognised, or are they well-functioning members of a species we have already characterised?'. Part of his story for how the naturalist goes about answering this question involves the naturalist seeing enough instances of the small form, spread over a wide enough area, to rule out the widespread action of a chemical toxin. This 
suggests they are not defective members of a known species. It is around this point that the naturalist will, in Thompson's words, 'be in a position to recognize a novel species of jellyfish, a hitherto unknown form of gelatinous life, a new way for physical particles to be trapped in a vortex of life-processes' (Thompson 2004: 48).

Suppose we find enough of these new individuals, over a wide enough range, to be confident that whatever environmental chemicals they are exposed to early in their lives are more or less the same as the environmental chemicals to which members of an alreadyrecognised species are exposed. In suggesting that we hereby have evidence for the existence of 'a novel species', Thompson can mean only that these kinds of observations establish a new T-species: it is consistent with noting 'an unknown form of gelatinous life' that we have characterised an unnoticed polymorphism that belongs within what biologists would think of as an already-known species. This, of course, does nothing to undermine Thompson's view: we have already seen that T-species-life forms-are quite different to the species that biologists deal with.

Even so, we must ask what makes it the case that we are now observing a new T-species. What determines that we are not dealing with a very common (albeit previously unrecognised) defective form of a recognised T-species? In Thompson's story there is no distinctive exogenous chemical that they are exposed to in ontogeny, which explains why our new jellyfish develop differently to the ones we are already familiar with. Still, they grow differently, and some developmental difference must explain this. Suppose we find that our new jellyfish all possess some distinctive pattern of genes, which explains their small size compared with the jellyfish we are already familiar with. What makes it the case 
that, rather than classing these as the genes that explain congenital abnormality within an already known T-species, we are instead supposed to class them as genes that explain proper development in a new T-species?

Biologists have various options for deciding whether to assign the newly discovered jellyfish form to a new biological species. There is still considerable disagreement among taxonomists regarding exactly what species membership consists in: some make it a matter of reproductive relations, others make it a matter of ancestry, others link it to the niche that organisms occupy, others define species membership in terms of clusters of genes held in common (see Wilson 1999). The techniques for species diagnosis issuing from these different technical concepts often agree in their verdicts over particular cases, which is one of the reasons why systematists are able to produce consensus taxonomies. This may give the impression that there are obvious facts that make it the case that our imaginary naturalist has indeed found a novel T-species, and which also rule out the alternative interpretation that what we are dealing with is a defective instance of a broader T-species. But the questions of what makes two individuals members of the same biological species, and what makes them members of the same T-species, are not the same. This point was established when we saw that the cryptic morph of Paracerceis sculpta is likely to be regarded by Thompson as a T-species, even though no taxonomist would regard it as one. Worries about underdetermination remain, in spite of Thompson's sketch of how our naturalist operates.

Having isolated a new T-species, Thompson then suggests how our naturalist might start to form well justified natural historical judgements about it. The naturalist notes, Thompson 
says, that these new jellyfish tend to have one hundred and forty-four tentacles, and begins to work on a book full of information such as this describing the newly recognised life-form. The result is that, 'Having given names to all one hundred and forty-four tentacles of the umbrella jelly in [the] monograph, [the naturalist] will be able, e.g., to say when an individual jelly is missing a tentacle, or when a tentacle is present but broken' (Thompson 2004: 54).

The naturalist can, of course, make various proclamations as to whether an individual has too few, or too many, tentacles. The question is whether these proclamations are well grounded. Suppose the naturalist finds a few more jellyfish that closely resemble the newlydescribed form in very many ways, except that they have a slightly different genome to the statistically common variety, and these genomic differences result in the jellyfish in question having 142 tentacles instead of the more usual 144. Suppose, further, that the jellyfish with 142 tentacles are slightly poorer at warding off predators than those with 144 tentacles. Is the naturalist supposed to say, 'These jellyfish are defective: they have 142 tentacles when they should have 144 '? Or is the naturalist supposed to say 'The newly-discovered 144tentacled Umbrella Jelly has 144 tentacles. The even-more-recently-discovered 142tentacled Umbrella Jelly only has 142 tentacles'? Or is the naturalist supposed to say 'The Umbrella Jelly has varying numbers of tentacles, either 142 or $144^{\prime}$ ?

It is not obvious what resources can settle this matter. Recall, yet again, that we cannot appeal to statistics: 'It is important to emphasize that...the natural historical judgments, are not mere reports of what is always or mostly or even often the case with jellies of this kind' (Thompson 2004: 50). The questions of how many distinct T-species we are dealing with, 
and which individual organism is a member of which, are also not settled in the standard ways that biologists might try to determine facts about biological species: we have already seen that T-species do not line up in a 1:1 way with biological species. Finally, we are not supposed to settle matters about whether a variant is a defective instance of one kind-as opposed to a normal instance of an alternative kind-by appealing to sociobiological facts about fitness.

In his discussion of jellyfish, Thompson summarises the steps that a naturalist goes through in arriving, finally, at a thorough understanding of a newly-discovered life-form. It is akin to a vague sketch which, over time and with patient observation of nature, eventually becomes detailed and colourful:

....you did this filling-in or colouring-in - which was both factual and evaluative, temporal and atemporal, general and particular-entirely on the basis of observation. (2004: 56)

My suggestion is that while observation prompts us to produce natural history judgements, strictly speaking it leaves them underdetermined. One explanation for this, consistent with Aristotelian realism, is that while there are facts of the matter about life forms, it is very hard for us to know what they are. Unfortunately it is not clear that there are any facts that could adjudicate in principle between alternative possible natural historical judgements, when we understand these judgements as descriptions of life-forms. Instead, the Aristotelian realist might try to argue that life-forms exist, but that there are no facts of the matter about some of the questions we might ask about them, especially when those 
questions are posed in very fine-grained ways. He or she might argue, for example, that while 'The human lives beyond puberty' is true, we should not expect there to be any fact of the matter regarding a specific claim like, 'The human lives to $85^{\prime}$. Let me stress, then, that my claim is not that the Aristotelian realist has no options. Even so, our discussion should make us consider an alternative explanation for the problems of underdetermination, uncongenial to the Aristotelian realist. Perhaps there are no Aristotelian life-forms for us to describe.

\section{FOOT ON ARISTOTELIAN NECESSITY}

Foot is concerned that Thompson, 'has not said enough to isolate the kind of proposition that will yield evaluations of individual organisms' (2001: 30). Her worry is Thompson has overlooked a form of natural historical judgement that does not carry normative connotations. For example, there are natural historical judgements that facilitate species identification, without giving any kind of performance specification. She imagines that we open a field guide to find the statement, 'The blue tit has a round patch on its head'. If this patch 'plays no part in the life of the blue tit', then an individual tit that lacks a round patch is not defective (ibid.).

This leads Foot to build her own positive account for how we can determine the content of Aristotelian categoricals proper, where we understand these judgements as having normative implications: 
We start from the fact that it is the particular life form of a species of plant or animal that determines how a given plant or animal should be: the Aristotelian categoricals give the 'how' of what happens in the life cycle of that species. And all truths about what this or that characteristic does, what its purpose or point is...must be related to this life cycle. The way an individual should be is determined by what is needed for development, self-maintenance, and reproduction: in most species involving defence, and in some the rearing of young. (2001: 32-2)

This means that Aristotelian categoricals solely concern those things that are 'needed' in the context of the life-cycle of the species. Hence Foot concludes that 'The peacock has a brightly coloured tail' expresses a normatively freighted natural historical judgement, while 'The blue tit has a round blue patch on its head' does not, even if both sentences are true. Returning to one of our earlier examples, Foot is likely to judge that 'The human lives until $110^{\prime}$ should be rejected, on the grounds that such long life is not needed in the context of the human life-cycle.

I have discussed Foot's approach elsewhere (Lewens 2010), and I do not propose to cover this ground in detail in this article. Instead, I offer a briefer summary of some problems that confront her position. She indicates that we begin by determining the general nature of the species' 'life cycle', and that once this is decided we can then determine which activities are 'necessary' in the context of that life cycle: 'As an illustration let us consider the Aristotelian categorical stating that the deer is an animal whose form of defence is flight. From this we know that it is a defect, a weakness, in an individual deer if it is slow of foot' (2001: 34). In 
other words, given that a feature of the deer's life cycle is having flight as a form of defence, being swift of foot is necessary for this form of defence.

In response to Foot, it remains unclear how we are to determine which forms of behaviour are truly 'necessary' in the context of some life cycle. A deer that cannot run fast might plausibly avoid predation by seeking cover and staying very still: so fast running is not strictly necessary for it to survive and reproduce, even if it is highly advantageous. Foot suggests that 'swiftness, as opposed to fierceness or camouflage, is what fits it to escape from its predators', perhaps indicating that she does not intend a strong reading of 'necessary', and that swiftness is a mark of a good deer because it contributes to avoidance of predators. This raises the question of what Foot might say about infanticide in chimpanzees: here, too, it seems unlikely that infanticide is strictly necessary as a reproductive strategy. Might she say that infanticide 'is what fits the chimp to secure nutrition, and to exclude rivals for reproductive opportunities'? Chimps do sometimes gain such benefits from infanticide, just as deer sometimes gain benefits from running from predators: the question of whether this natural history judgement is true seems open.

It is also unclear how we are to determine the general nature of the species life cycle in the first place, from which claims about these necessities are to be derived. Does infanticide, for example, belong in the chimp's life cycle? In his defence of Foot and Thompson, Lott claims that:

...it is characteristic of birds of paradise that the males attract mates via their long tails. That is part of how they find mates, and therefore part of how they achieve the 
end of reproduction. The long tails of mates, then, do 'play a part' in the life cycle of the species. Given that, we could formulate an Aristotelian categorical along the lines of 'the male bird of paradise attracts mates using his long tail.' (2012: 364-5)

How are we to establish that it is 'characteristic' of birds of paradise to attract mates via their long tails? To pronounce a long tail 'characteristic' in this normatively significant sense does not entail that most individual male birds of paradise attract mates like this, only that they should do so. How, then, are we to adjudicate in a dispute between two imaginary naturalists who disagree over whether it is 'characteristic' of chimpanzees to kill newborns, given that this is intended as a claim about the chimpanzee's life-form, distinct from truths about specific chimpanzees?

Lott proposes that we see how well the natural historical judgement in question can be integrated into a system of such judgements that describe the life-cycle as a whole (2012: 373). But since these judgements are only tied loosely to facts concerning specific traits of token organisms (for large numbers of organisms may be malfunctioning in various respects) it may be possible to maintain many different systems of incompatible judgements. It is certainly far from clear that 'the chimpanzee practices infanticide' will be decisively supported or undermined as it is assessed for its fit with plausible systems of natural historical judgements. Foot's account does not seem to avoid our problems of underdetermination.

\section{A FALSE FRIEND: FOLK ESSENTIALISM}


Work in psychology seems to show that humans of many ages routinely make the kind of simultaneously normative and descriptive judgements that Thompson and Foot draw our attention to. Scott Atran and colleagues argue that people 'presume the biological world to be partitioned...into non-overlapping kinds, each with its own unique causal essence, or inherent underlying nature, the visible products of which may or may not be readily perceived' (Atran et al 1997, see also Atran 1990). Similarly, Gelman and Hirschfeld suggest that, '[f]our-year-old children act like essentialists, assuming that members of a category share an innate potential and that innate potential can overcome a powerful environment' (1999: 418).

Such psychological tendencies can explain why we endorse judgements with just the features that Thompson points to. We seem to assume that species members have intrinsic properties which (i) determine their membership of the species in question and (ii) dispose them to develop the proper traits of the species. What makes each dog a dog is its possession of a set of intrinsic properties which, when they direct development properly, result in a creature that possesses typically 'doggy' properties. Since these essences can 'mis-fire', it is possible for any number of true dogs to fail to have the properties a dog ought. Description of the nature of the dog, on this view, is description of what a proper dog is like, it does not reduce to any statistical claim about what actual dogs are like in terms of their manifested properties, and it has the implication that individual dogs that do not manifest the proper dog nature are defective (see Leslie 2017).

While research from Atran, Gelman and Hirschfeld is broadly supportive of the thought that many humans describe life-forms in ways that carry the normative connotations that 
Thompson and Foot discern, it does not help with the neo-Aristotelian claim that these lifeforms or species natures are real (Lewens 2012). Atran (1990) takes it as obvious that his research exposes a widely held error. On his view, there are no intrinsic essences that make individuals members of the species to which they belong. The most natural interpretation of this line of work, once again, is that while we might talk as though there are life-forms, in reality there are none.

\section{THE TRANSCENDENTAL ARGUMENT FOR LIFE-FORMS}

My arguments have not yet addressed what I take to be the most important element of Thompson and Foot's positive case for their view. Their view is that the practice of biology presupposes the truth of natural history statements, because it is impossible to describe any individual object as engaged in any kind of 'vital' activity - that is to say, we cannot describe it as an organism at all-unless we consider it as an instance of a life-form:

...the existence of life-forms, in the sense employed by Thompson, is not a contingent fact about the development of the present set of living organisms, as is the existence of genera and of phyla. The existence of a life-form is presupposed whenever we identify anything as an organism. (Hacker-Wright 2009: 311)

I consider two versions of this argument.

Foot's version 
Foot's thought, which she credits to Thompson, is that natural historical judgements tell us how creatures of a given kind live. Without reference to such judgements, we cannot determine what activity a given organism is engaging in. For example, we simply cannot say whether a process in which plant matter is reduced to pulp and then squirted out of the organism is (i) the construction of a building material or (ii) excretion of nutritional waste or (iii) a defence mechanism (Foot 2001: 28).

To evaluate this argument, let us distinguish what we might call macroprocesses-large scale processes such as nutrition, defence, or construction-from microprocesses - the constituent elements of such processes that might involve the reduction of plant matter to pulp. Foot is correct that a biological macroprocess cannot be properly typed merely by reference to the intrinsic microprocesses that enable it, and which occur within the bounds of the organism. First, a given microprocess-reduction of food matter to pulp-might be recruited into many different macroprocesses in different lineages. Second, a given macroprocess-defence-might be realised by many different microprocesses in different lineages. Third, and most important, the question of whether a microprocess is involved in nutrition or defence is dictated by the function of the macroprocess of which it is an element. This means that we cannot tell what the function of a token macroprocess is simply by looking at the actual causal capacities of its constituent microprocesses, because those microprocesses might be malfunctioning.

This version of the transcendental argument can be answered by appeal to reductive accounts of biological function. For example, variants of the selected-effects account of biological function (e.g. Neander 1991 inter alia) hold that the function of a given 
microprocess depends on what the downstream effects of that process have been on past survival and reproduction. These views spell out precisely how we can determine whether a process of crushing food into pulp is an instance of 'skunk-like defence' or elimination of waste: we simply need to look at the past downstream effects of the process, in environmental context, on the fitness of the organism in question. These views also give us the resources to assign a microprocess as an instance of 'skunk-like defence' even if, for some reason, effective squirting of a predator is not possible because the process is malfunctioning. We simply ask, first, whether the trait in question is homologous with other token traits in the same lineage, and then we ask what tokens of that trait type have done in the recent past to explain their maintenance in the population. The microprocess has the function of skunk-like defence if this is the effect that explains the presence of token microprocesses of the same (homologous) type in the lineage in question. In summary, while Foot succeeds in pointing to the need to relate microprocesses to broader ecological contexts if we are to determine what their functions are, this version of the transcendental argument does not succeed in showing that the very practice of biology presupposes the truth of an Aristotelian conception of species natures.

Thompson's version

Thompson $(1995,2008)$ offers a different version of the transcendental argument for Aristotelian realism. His claim (in a chapter called 'Can Life be Given a Real Definition?') is that there is no adequate definition that can be given in purely biochemical terms of what it is for a thing to be living. He seeks to establish this by showing a hidden circularity in all standard accounts of what it is for a thing to be alive. For example, we might suggest that a 
living thing is something that (in his terms) 'grows and develops'; but then, since as a matter of fact a token living entity might die early and predictably from congenital causes, we must give an account of what it is meant to develop towards. Alternatively, we might suggest that a living thing is 'self-reproducing'. Again, though, since in actual fact an organism might be sterile, or it might produce an entity that lacks the capacity to grow effectively, we must have in mind some standard of proper reproduction. Thompson considers additional proposals, and concludes that in every case to identify something as living presupposes that we think of it as an instance of a life-form, and that we must understand such life-forms in normative terms. The life-form itself specifies a series of proper developmental stages, vital activities set in ecological context and so forth. This reference to a life-form, says Thompson, is ineliminable in the practice of biology, and no reductive approach to specifying the lifeform can succeed.

Groll and Lott express his general position nicely:

Our understanding of what constitutes an organism's maturation is not a statistical summary. Rather the relevant concept of 'mature' implies a non-statistical sense of how things stand with organisms of a particular kind - a particular conception of 'what they do' or 'how things go with them' when they mature.... (Groll and Lott 2015: 633)

They conclude that '....any conception of a life-form is a conception of the proper (uninterrupted, undistorted) unfolding of its vital activities'. 
One way to respond to Thompson would be to defend a fully reductive account of what it is to be alive. In other words, we would show that reference to the normative notion of a lifeform can be eliminated, or perhaps that the norms and teleological notions invoked by Thompson can be analysed in a reductive manner related to the selected effects account of function. I do not want to take a stand on whether this is possible. Instead, I suggest that even if we agree with Thompson and his defenders that such a reductive project will not work, this still does not suffice to defend the realist interpretation of Aristotelian species natures, or 'life-forms'.

My strategy, drawing on work on a loosely Kantian approach to the heuristic function of teleological judgement and of a goal-directed conception of the organism, is to suggest that Thompson's account shares the general problem of many transcendental arguments. The most Thompson's argument establishes is that we must think of organisms as instances of life-forms. This does not entail that there are such life-forms. We can develop this response by considering an interpretation of Kant on teleology which we owe to Breitenbach (2009) and Lewens (2007).

The case for the Kantian conception of goal-directedness begins where Thompson does. For many individuals within many species, the great majority of sperm and eggs never combine to produce organisms at all. Many token embryos do not survive beyond early developmental stages, others survive for a multitude of different, longer periods, in a variety of different configurations. How is the embryologist meant to investigate the living world? If she focuses on what is statistically normal she may end up focussing on what is biologically uninteresting. Suppose, instead, that the embryologist simply attempted to give 
cause-by-cause narratives for every one of these token outcomes in terms of the interactions of the various biochemical contributors to development. This vast catalogue of mechanistic explanations would be unmanageable.

Some kind of bringing-to-order is required: something like a set of standard reference points which the embryologist will focus on in her explanatory aims. By hypothesis, there is little value in focusing on the statistically most common developmental outcomes, for they are likely to be short-lived. Instead, our embryologist is likely to focus on those which attain a healthy adult form. But note, just as Thompson does, that the classification of some organisms' developmental trajectories as 'short-lived' and others as 'long-lived' or 'healthy' presupposes some kind of standard for what development should look like. In designating some set of outcomes as the normal representative adult forms we thereby privilege a subset of outcomes as the 'proper' ones. They then act as reference points when we wish to construct explanations for other developmental outcomes that are, by reference to those standards, truncated, aberrant, anomalous or defective.

These reference points guide biological research, and they allow manageable depictions of biological processes via standardised representations of developmental sequences that in reality vary from individual to individual. For them to do their job, they cannot be wholly uninformed by encounters with the organic world. It would be of no pragmatic use to claim that there is a fourth male form of Paracerceis sculpta that is never instantiated in nature, or to claim that since the mouse lives to 30 years of age all mice are defective. Instead, for the heuristic functions of these standards to be realised it is essential that posited developmental endpoints are constructed in light of what is actually observed as token 
organisms change over time. So some kind of discipline is exerted by encounters with the biological world as investigators articulate life-forms with pragmatic value.

Even so, this Kantian view takes a heuristic approach to these notions of normal or proper end states: it does not require that we understand them in realist terms. They can be understood as projections onto nature, or constructions that draw from encounters with nature. They enable us to organise our knowledge of the natural world, and they coordinate further inquiry into the biochemical mechanisms of development. The appeal to proper developmental trajectories does not explain development, hence there is no requirement that there be facts about which developmental trajectories are proper. The appeal we make to proper end-points gives us a way of organising the subject matter for what will then be a set of causal mechanical explanations for how a fertilised egg comes to acquire new capacities over time. But while their roles are pragmatic, these end-points are also indispensable, for biologically inquiry is practically impossible without such developmental standards.

For these reasons, the Kantian position I sketch here does not meet even the minimal requirements for realism that I suggested (in section two) were present in Thompson and Foot's work. Biological investigators must articulate the nature of some discrete number of life-forms to serve as standards, and yet there are no life-forms. There are only token organisms with spectacular variability. The Kantian position tells us that unless we sort the organic world into a discrete set of life-forms, each with a 'proper' end state, we cannot get started on the business of biological explanation. For that reason, the Kantian view does not purport to resolve underdetermination problems by giving us a way to determine the true 
answer to a question like, 'Does a proper chimp practice infanticide or not?'. Instead, the Kantian position holds that there is no answer to this question, because there are no lifeforms, hence there are no facts of the matter about them. The Kantian view predicts the phenomenon of underdetermination and explains why it cannot be resolved.

\section{FOR KANT, NOT ARISTOTLE}

I have not tried to argue that the Kantian projectivist view is correct, for I have not tried to argue here against the possibility of a wholly reductive definition of what it is for a thing to be living. I have not offered a detailed defence of the Kantian view: instead, my aim has been to indicate its potential attractions and thereby encourage further investigation of it. If we agree with Thompson that biological enquiry presupposes that we conceive of the world in terms of some number of proper end-points, or some number of ways of making a living in nature, then the Kantian projectivist position is a significant competitor to neoAristotelian realism. Indeed, the Kantian projectivist view is better supported insofar as it explains why the realist position faces the problems it does, it evades those problems itself, and it does all of this in a parsimonious way that avoids commitment to facts about lifeforms or species natures.

Like neo-Aristotelian realism, the Kantian projectivist view delivers the result that the practice of biology is impossible unless we conceive of the organic world in terms of some limited number of proper ways for organisms to make their ways in the world. It also has the consequence that our talk about these life-forms is not reducible in any straightforward way to claims about statistical norms or evolutionary history. It even shares with neo- 
Aristotelianism the consequence that these judgements about life-forms have a non-moral form of normative content, for as we have seen they express what it is for organisms of a certain kind to develop properly, even if many organisms of that kind do not in fact develop in the specified way. But the Kantian projectivist view is not a realist view. Because of that, it is not well-suited to Foot's more general project of casting ethical judgement as a form of judgement that succeeds in stating the facts.

If 'life-forms' are simply projections-constructed images of proper life and development that organise and facilitate our enquiry - then of course the details of these projections will need to be informed by our encounters with the natural world in just the way that Thompson's account of enquiry into the lives of jellyfish suggests. Such life-forms would not facilitate enquiry, communication and explanation if their construction were entirely unconstrained by specific developmental and evolutionary events as we find them. It is also quite possible that our choice of which developmental end-points to anoint as 'proper' may sometimes be coloured by our prior ethical evaluations of-for example-what kind of behaviour we find admirable in chimps, or elephant seals. The Kantian projectivist view thus has the resources to explain the normative content associated with our claims about 'life forms'. It is also no surprise, on this view, to find that there are several alternative, equally productive or reasonable, ways of constructing these images of 'life-forms', with no facts that discriminate between alternative visions of what, for example, a 'proper' chimp is like.

The Kantian projectivist view explains the appeal of Thompson's transcendental argument, while also predicting the forms of underdetermination outlined in the middle parts of this article. It offers a general image of the natural world that explains what is attractive about 
the Aristotelian realist position, while also accounting for its limitations and the puzzlements to which that view gives rise. ${ }^{4}$

\section{REFERENCES}

Amundson, R. and G. Lauder (1994) 'Function without Purpose', Biology and Philosophy, 1994: 443-469.

Arcadi, A. and R. Wrangham (1999) 'Infanticide in Chimpanzees', Primates, 40: 337-351.

Atran, S. (1990) Cognitive Foundations of Natural History. Cambridge: Cambridge University Press.

Atran, S., Estin, P., Coley, J., \& Medin, D. (1997) ‘Generic species and basic levels: essence and appearance in folk biology', Journal of Ethnobiology, 17, 17-43.

Breitenbach, A. (2009) 'Teleology in Biology: A Kantian Perspective', Kant Yearbook, 31-56.

Darwin, C. (1877/2004) The Descent of Man, Second Edition. Edited and introduced by J Moore and A Desmond. London: Penguin.

Fitzpatrick, W. (2000) Teleology and the Norms of Nature. New York: Garland Publishing. Foot, P. (2001) Natural Goodness. Oxford: Oxford University Press.

Hacker-Wright, J. (2009) 'What is Natural about Foot's Ethical Naturalism?', Ratio, 22: 308321.

\footnotetext{
${ }^{4}$ Thanks to the two generous and insightful referees from this journal for comments, as well as to audiences at the University of Paris Nanterre, University of Paris 1 PanthéonSorbonne, The University of Exeter, and finally to Micah Lott for comments at a workshop on inclusive fitness in Cambridge.
} 
Hawkes, K. (2003) 'Grandmothers and the Evolution of Human Longevity', American Journal of Human Biology, 15: 380-400.

Gelman, S., \& Hirschfeld, L. (1999) 'How Biological is Essentialism?', in S. Atran \& D. Medin (eds.) Folkbiology, 403-445. Cambridge: MIT Press.

Glackin, S. (2016) 'Three Aristotelian Accounts of Disease and Disability', Journal of Applied Philosophy, 33: 311-326.

Griffiths, P. (1993) 'Functional Analysis and Proper Functions', British Journal for the Philosophy of Science, 44: 409-422.

Groll, D. and M. Lott (2015) 'Is There a Role for "Human Nature" in Debates about Human Enhancement?', Philosophy, 90: 623-651.

Lewens, T. (2007) 'Functions' in M. Matthen and C. Stephens (eds.) Handbook of Philosophy of Science: Philosophy of Biology. 525-47. Amsterdam: Elsevier.

Lewens, T. (2010) 'Foot Note', Analysis, 70: 468-473.

Lewens, T. (2012) 'Human Nature: The Very Idea', Philosophy and Technology, 25: 459-474.

Lott, M. (2012) ‘Have Elephant Seals Refuted Aristotle?', Journal of Moral Philosophy, 9: 353-375.

Neander, K. (1991) 'Functions as Selected Effects: The Conceptual Analyst's Defense', Philosophy of Science, 58: 168-184.

Shuster, S. (1987) 'Alternative reproductive behaviors: Three discrete male morphs in Paracerceis sculpta', Journal of Crustacean Biology, 7: 318-327.

Thompson, M. (1995) 'The Representation of Life', in R. Hursthouse, G. Lawrence and W. Quinn (eds.) Virtues and Reasons, 247-96. Oxford: Oxford University Press.

Thompson, M. (2004) ‘Apprehending Human Form’, in A. O’Hear (ed.) Modern Moral Philosophy, 47-74. Cambridge: Cambridge University Press. 
Thompson, M. (2008) Life and Action: Elementary Structures of Practice and Practical Thought. Cambridge, MA: Harvard University Press.

UN (2015) World Population Prospects: The 2015 Revision. Volume 1: Comprehensive Tables. New York: United Nations.

Walsh, D. and A. Ariew (1996) 'A Taxonomy of Functions', Canadian Journal of Philosophy, 26: $493-541$.

Walsh, D. (2006) 'Evolutionary Essentialism', British Journal for the Philosophy of Science, 57: 425-448.

Walsh, D. (2015) Organisms, Agency and Evolution. Cambridge: Cambridge University Press. Wilson, R. (1999) Species: New Interdisciplinary Essays. Cambridge, MA: MIT Press.

Woodcock, S. (2015) ‘Neo-Aristotelian Naturalism and the Indeterminacy Objection’, International Journal of Philosophical Studies, 23: 20-41.

University of Cambridge, UK. 